\title{
Colonic malakoplakia in a liver transplant recipient
}

\author{
Peter TW Kim $M D^{1}$, Jennifer E Davis $M B^{2}$, Siegfried R Erb $M D^{3}$, Eric $M$ Yoshida $M D^{3}$, Urs $P$ Steinbrecher $M D^{3}$
}

\begin{abstract}
PTW Kim, JE Davis, SR Erb, EM Yoshida, UP Steinbrecher. Colonic malakoplakia in a liver transplant recipient. Can J Gastroenterol 2007;21(11):753-755.
\end{abstract}

\begin{abstract}
Malakoplakia is a rare inflammatory condition seen in transplant patients. There are two previously reported cases of malakoplakia involving the gastrointestinal tract in liver transplant patients. The present paper reports a case of colonic malakoplakia in a 58-year-old woman, a liver transplant recipient who was receiving immunosuppressive drugs. She presented with chronic diarrhea while on tacrolimus. There was no history of antecedent infection. Colonoscopy showed patchy mucosal edema, but no discrete yellow plaques or nodules. The diagnosis was made by colon biopsies, which showed chronic inflammation with many histiocytes containing Michaelis-Gutmann bodies. Although rare, malakoplakia is one of many potential causes of diarrhea in a transplant patient. The present case indicates that malakoplakia may be associated with chronic diarrhea, even if there are no macroscopic lesions seen during colonoscopy.
\end{abstract}

\author{
Une malacoplasie colique chez une greffée du \\ foie
}

La malacoplasie est une pathologie inflammatoire rare qu'on observe chez les greffés. On a déjà déclaré deux cas de malacoplasie dans le tube digestif de greffés hépatiques. Le présent article présente un cas de malacoplasie colique chez une femme de 58 ans greffée du foie qui recevait des immunosuppresseurs. Elle a consulté en raison d'une diarrhée chronique alors qu'elle prenait du tacrolimus. Elle n'avait pas d'antécédents d'infection. La coloscopie a révélé un œdème muqueux à foyers disséminés, sans plaques ou nodules jaunâtres discrets. Des biopsies du côlon ont permis de poser le diagnostic, car elles ont mis au jour une inflammation chronique accompagnée de nombreux histiocytes contenant des corps de MichaelisGutmann. Bien qu'elle soit rare, la malacoplasie est l'une des nombreuses causes potentielles de diarrhée chez un greffé. Le présent cas indique que la malacoplasie peut s'associer à une diarrhée chronique, même si aucune lésion malacoplasique n'est observée pendant la coloscopie.

Key Words: Liver transplant; Malakoplakia

$\mathrm{M}$ alakoplakia, derived from the Greek words 'malakos', which means soft, and 'plax', which means plaque, is a rare inflammatory condition characterized by the presence of yellow-brown plaques comprised of aggregates of histiocytes. The histiocytes contain Michaelis-Gutmann bodies, which are pathognomonic inclusions containing accumulated bacterial products $(1,2)$. The etiology of malakoplakia is still undetermined, but is thought to be caused by a dysfunction of bacterial clearance by neutrophils and macrophages (3). It has been associated with immunodeficiency states such as malignancy (1) and transplantation (3). Those patients often have coexisting Gram-negative infections (4). Malakoplakia is most commonly found in the genitourinary tract, but has been reported in the gastrointestinal tract $(4,5)$, the lung (6) and the skin (7). Malakoplakia has rarely been reported in the setting of liver transplantation. The first case of malakoplakia in a liver transplant patient was reported (8) in 1995, and it involved the distal ileum and the mesentery. Two additional reports in liver transplant patients, involving the kidney (9) and the sigmoid colon (10), have been published. The present report describes a case of malakoplakia of the colon in a liver transplant recipient; this is the third reported case of post-liver transplant malakoplakia that involves the gastrointestinal tract and the second reported case that involves the colon.

\section{CASE PRESENTATION}

A 58-year-old Korean woman had undergone a cadaveric orthotopic liver transplant three years previously for hepatitis Cinduced cirrhosis and portal hypertension. Her post-transplant recovery period was complicated by ischemia-reperfusion injury, documented during a liver biopsy, and further confirmed by multiple strictures of intrahepatic and extrahepatic biliary ducts upon endoscopic retrograde cholangiopancreatography. She developed jaundice, ascites and pruritus, and was relisted for a second liver transplant. She was maintained on $2 \mathrm{mg}$ of tacrolimus twice daily, $200 \mathrm{mg}$ of spironolactone daily, $120 \mathrm{mg}$ of furosemide daily, $150 \mathrm{mg}$ of rifampin twice daily and $500 \mathrm{mg}$ of ursodiol twice daily. The tacrolimus dosage ranged from $3 \mathrm{ng} / \mathrm{mL}$ to $6 \mathrm{ng} / \mathrm{mL}$. She was not maintained on any other immunosuppressive agents.

The patient had first reported diarrhea approximately one year previously. This progressed to the point that, for two months previously, she had reported up to 20 episodes per day of watery diarrhea. She had mild peripheral edema. The patient reported no antecedent travel history and no change in diet. Stool cultures, ova and parasite testing, and a Clostridium difficile toxin assay were negative. The patient was negative for the cytomegalovirus antigen. Her serum albumin level was $22 \mathrm{~g} / \mathrm{L}$. She did not have any significant weight loss. The

\footnotetext{
${ }^{1}$ Department of Surgery; ${ }^{2}$ Department of Pathology and Laboratory Medicine; ${ }^{3}$ Division of Gastroenterology, Department of Medicine,

University of British Columbia, Vancouver, British Columbia

Correspondence: Dr Eric M Yoshida, Division of Gastroenterology, Vancouver General Hospital, 5153-2775 Laurel Street, Vancouver,

British Columbia V5Z 1M9. Telephone 604-875-5371, fax 604-875-5447, e-mail eric.yoshida@vch.ca

Received for publication June 13, 2006. Accepted December 5, 2006
} 

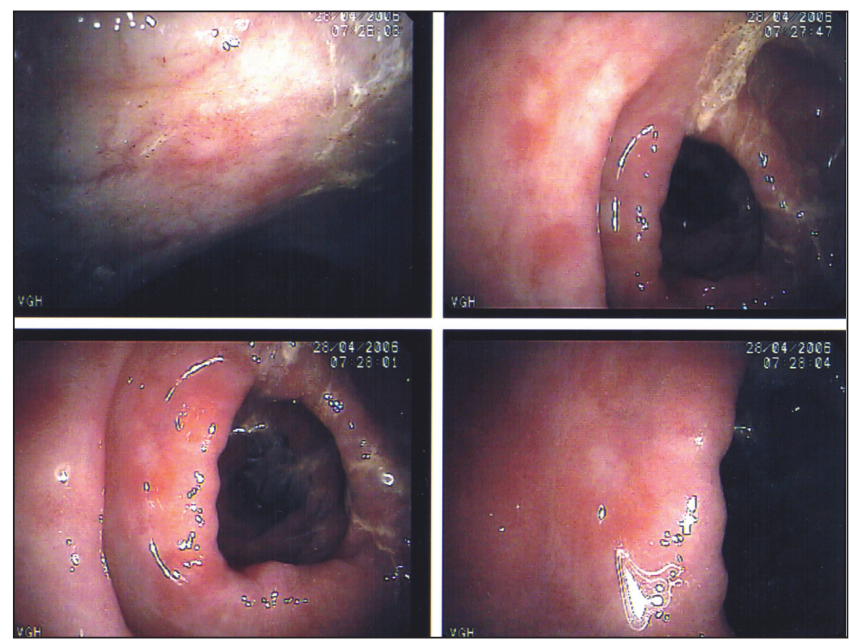

Figure 1) Colonoscopic appearance of colonic malakoplakia in a liver transplant recipient, characterized by generalized edema, patchy erythema and multiple smooth nodules

patient complained of fatigue, but she was not in acute distress. An ultrasound of the abdomen did not reveal any ascites.

The patient underwent a colonoscopy with biopsies. The mucosa throughout the colon appeared edematous, with a patchy loss of the vascular pattern and mild, patchy erythema, as illustrated in Figure 1. There was a slight yellowish tinge to some of the erythematous patches, and several had pale, targetlike centres. Biopsies revealed active inflammation, cryptitis, occasional crypt abscesses and sheets of histiocytes with Michaelis-Gutmann bodies (Figure 2). Erythematous, edematous areas, as well as intervening mucosa that appeared normal, were both involved. The cytomegalovirus immunostain was negative, and no infectious agents were identified on hematoxylin and eosin stain.

\section{DISCUSSION}

The gastrointestinal tract is the second most common site of involvement by malakoplakia, and most of those cases involve the colon and the rectum (11). Malakoplakia of the colon has a distinctive gross and microscopic appearance. Colonic involvement can be either segmental or diffuse. In the early stages, the lesions appear soft, flat and tan-coloured. Later, they can develop into raised, tan-grey and hyperemic lesions (10). Histologically, malakoplakia is characterized by aggregates of large histiocytes (known as von Hansemann cells) with intracellular and extracellular inclusions (known as Michaelis-Gutmann bodies), which are phagolysosomes that have become encrusted with calcium and iron salts. These findings are pathognomonic and establish the diagnosis of malakoplakia.

The etiology of malakoplakia is still not fully understood, but there is an association with Gram-negative bacterial infections, particularly with Escherichia coli. The likely mechanism of malakoplakia is defective lysosomal processing of microorganisms by macrophages in the accumulation of debris in lysosomes and subsequent mineralization.

Another potential contributing factor to the development of malakoplakia is an impaired immune response (eg, immunosuppression used to prevent rejection in organ transplant patients). In a review by Long and Althausen (12), approximately $40 \%$ of

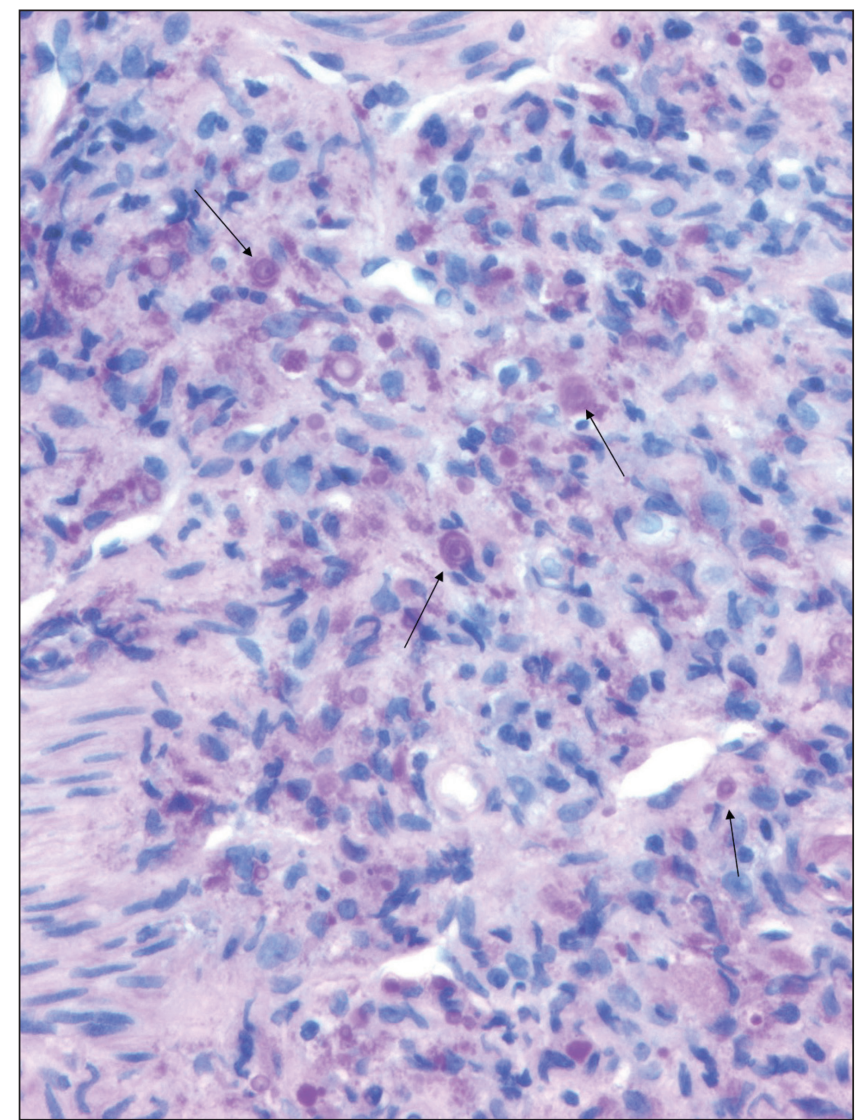

Figure 2) Microscopic appearance of colonic malakoplakia in a liver transplant recipient, as illustrated by the periodic acid-Schiff stain with diastase digestion, demonstrating the Michaelis-Gutmann bodies (arrows)

malakoplakia cases that did not involve the urinary tract were associated with immunosuppression. In a review of the literature, there have been three cases (8-10) of malakoplakia in liver transplant recipients. Two of those case reports $(9,10)$ involved the gastrointestinal tract (the small bowel and mesentery, and the sigmoid colon). The indications for transplantation included hepatitis C infection and hepatocellular carcinoma. The clinical presentation of malakoplakia included small bowel obstruction and chronic diarrhea. No coexisting infection was reported, although the patient described by Rull et al (8) died four weeks after a laparotomy for bowel obstruction secondary to pneumonia that was caused by Pseudomonas species. In the patient described in the present paper, the degree of immunosuppression was relatively mild, consisting of tacrolimus monotherapy with low trough drug levels. Perhaps her decompensated liver disease contributed to her susceptibility to malakoplakia. There have been no reports of tacrolimus directly inducing lysosomal dysfunction or malakoplakia.

Attempts at treatment of malakoplakia have included two main approaches: the administration of a cholinergic agonist to improve macrophage function, and antibiotic therapy. Abdou et al (13) reported a patient with rectal and retroperitoneal malakoplakia. They documented that the patient had monocytes that had decreased bactericidal activity against E coli, abnormally large lysosomal granules, low levels of cyclic GMP in mononuclear cells and poor release of betaglucuronidase in a bactericidal assay (13). Low levels of cyclic 
GMP in cultured malakoplakia cells were corrected by treatment with carbachol, a cholinergic agonist. The patient's clinical course improved after oral treatment with bethanechol chloride. The rationale for antibiotic therapy is to administer antibiotics that concentrate in macrophages. van Furth et al (14) reported two patients with malakoplakia who were treated with ciprofloxacin and experienced regression of their lesions with long-term therapy. Yousif et al (15) also reported a case of rectal malakoplakia that was successfully treated with a six-month course of ciprofloxacin, along with a reduction of immunosuppression (15).

\section{REFERENCES}

1. Stanton MJ, Maxted W. Malacoplakia: A study of the literature and current concepts of pathogenesis, diagnosis and treatment. J Urol 1981;125:139-46.

2. van der Voort HJ, ten Velden JA, Wassenaar RP, Silberbusch J. Malacoplakia. Two case reports and a comparison of treatment modalities based on a literature review. Arch Intern Med 1996;156:577-83.

3. Streem SB. Genitourinary malacoplakia in renal transplant recipients: Pathogenic, prognostic and therapeutic considerations. J Urol 1984;132:10-2.

4. Bellin MF, Darchen MA, Hoang C, et al. Rectal malacoplakia in renal transplantation: MR features. J Comput Assist Tomogr 1994;18:975-8.

5. Berney T, Chautems R, Ciccarelli O, Latinne D, Pirson Y, Squifflet JP. Malakoplakia of the caecum in a kidney-transplant recipient: Presentation as acute tumoral perforation and fatal outcome. Transpl Int 1999;12:293-6.

6. Colby TV, Hunt S, Pelzmann K, Carrington CB. Malakoplakia of the lung: A report of two cases. Respiration 1980;39:295-9.

7. Palou J, Torras H, Baradad M, Bombi JA, Martin E, Mascaro JM. Cutaneous malakoplakia. Report of a case. Dermatologica 1988;176:288-92.

\section{CONCLUSIONS}

The present paper presents the third reported case of malakoplakia of the gastrointestinal tract in a liver transplant recipient. The presentation of malakoplakia depends on the location and the degree of involvement. Two of the three reported patients presented with diarrhea. Although rare, malakoplakia is one of the many potential causes of diarrhea in a liver transplant patient and can be readily diagnosed from mucosal biopsies of the colon. It is typically a benign, self-limited condition that responds to antibiotic therapy and to a reduction of immunosuppression.

8. Rull R, Grande L, Garcia-Valdecasas JC, et al. Malakoplakia in the gastrointestinal tract of a liver transplant recipient. Transplantation 1995;59:1492-4.

9. Kamishima T, Ito K, Awaya H, Mitchell DG. MR imaging of bilateral renal malacoplakia after liver transplantation. AJR Am J Roentgenol 2000;175:919-20.

10. Weinrach DM, Wang KL, Cisler JJ, Diaz LK. Pathologic quiz case A 54-year-old liver transplant recipient with diffuse thickening of the sigmoid colon. Malakoplakia of the colon associated with liver transplant. Arch Pathol Lab Med 2004;128:e133-4.

11. McClure J. Malakoplakia of the gastrointestinal tract. Postgrad Med J 1981;57:95-103.

12. Long JP Jr, Althausen AF. Malacoplakia: A 25-year experience with a review of the literature. J Urol 1989;141:1328-31.

13. Abdou NI, NaPombejara C, Sagawa A, et al. Malakoplakia: Evidence for monocyte lysosomal abnormality correctable by cholinergic agonist in vitro and in vivo. N Engl J Med 1977;297:1413-9.

14. van Furth R, van't Wout JW, Wertheimer PA, Zwartendijk J. Ciprofloxacin for treatment of malakoplakia. Lancet 1992;339:148-9.

15. Yousif M, Abbas Z, Mubarak M. Rectal malakoplakia presenting as a mass and fistulous tract in a renal transplant patient. J Pak Med Assoc 2006;56:383-5. 


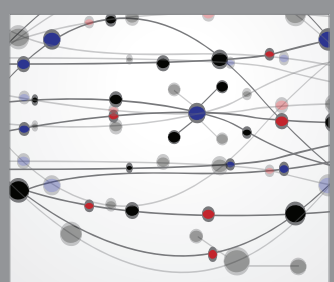

The Scientific World Journal
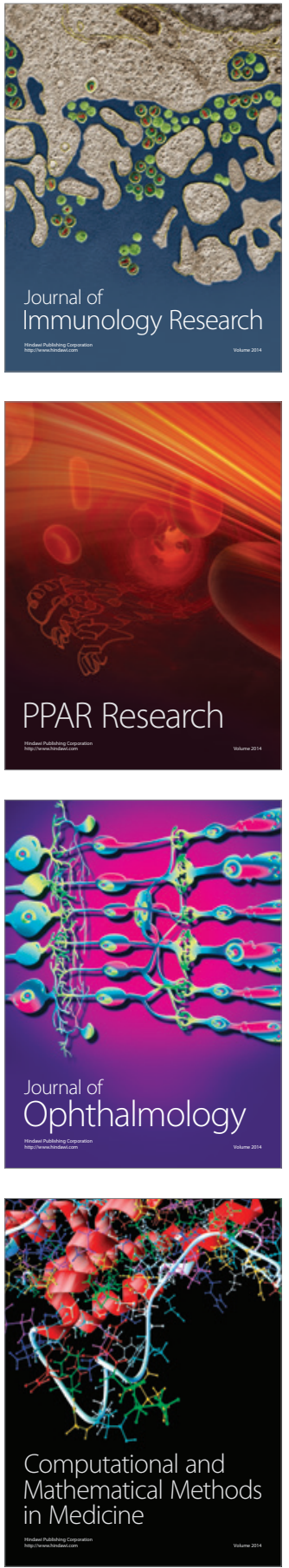

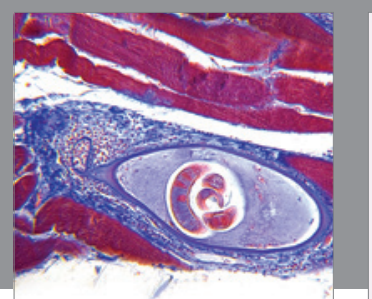

Gastroenterology Research and Practice

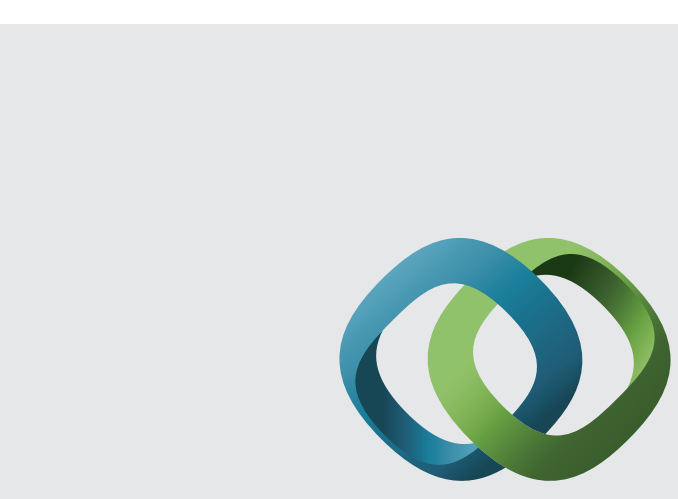

\section{Hindawi}

Submit your manuscripts at

http://www.hindawi.com
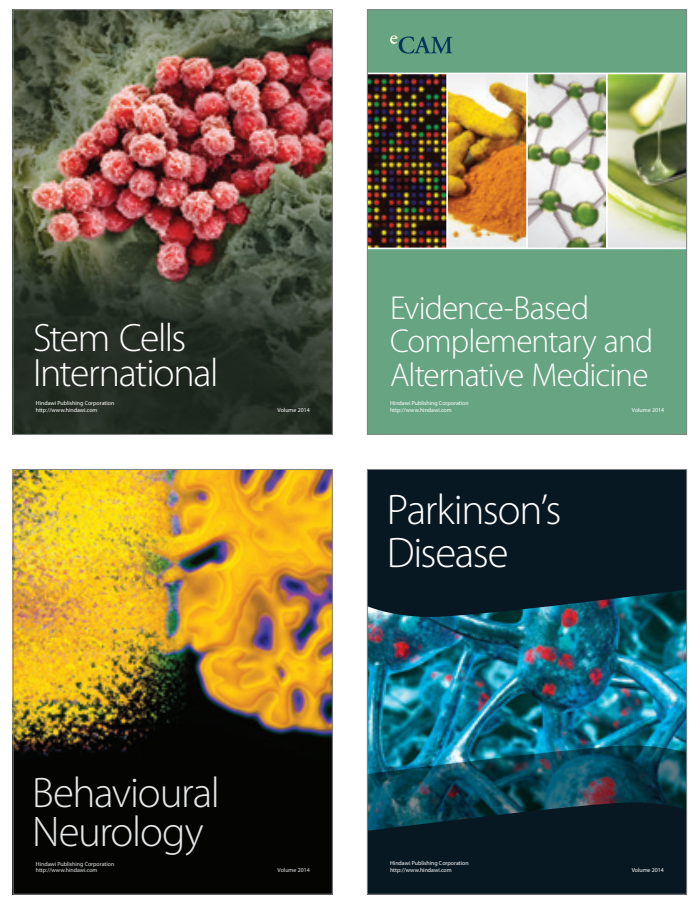
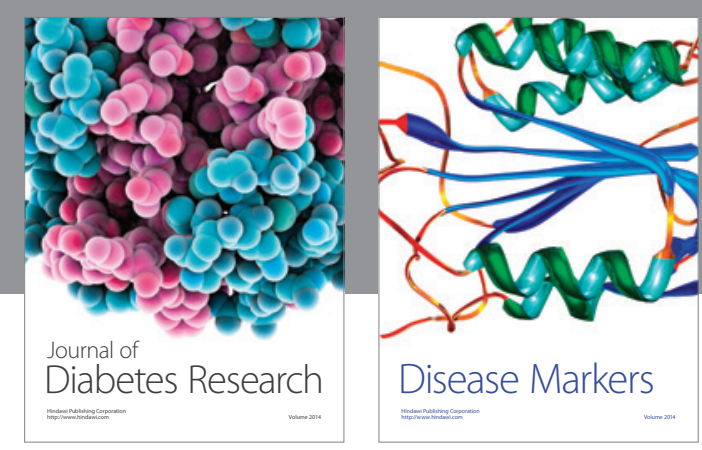

Disease Markers
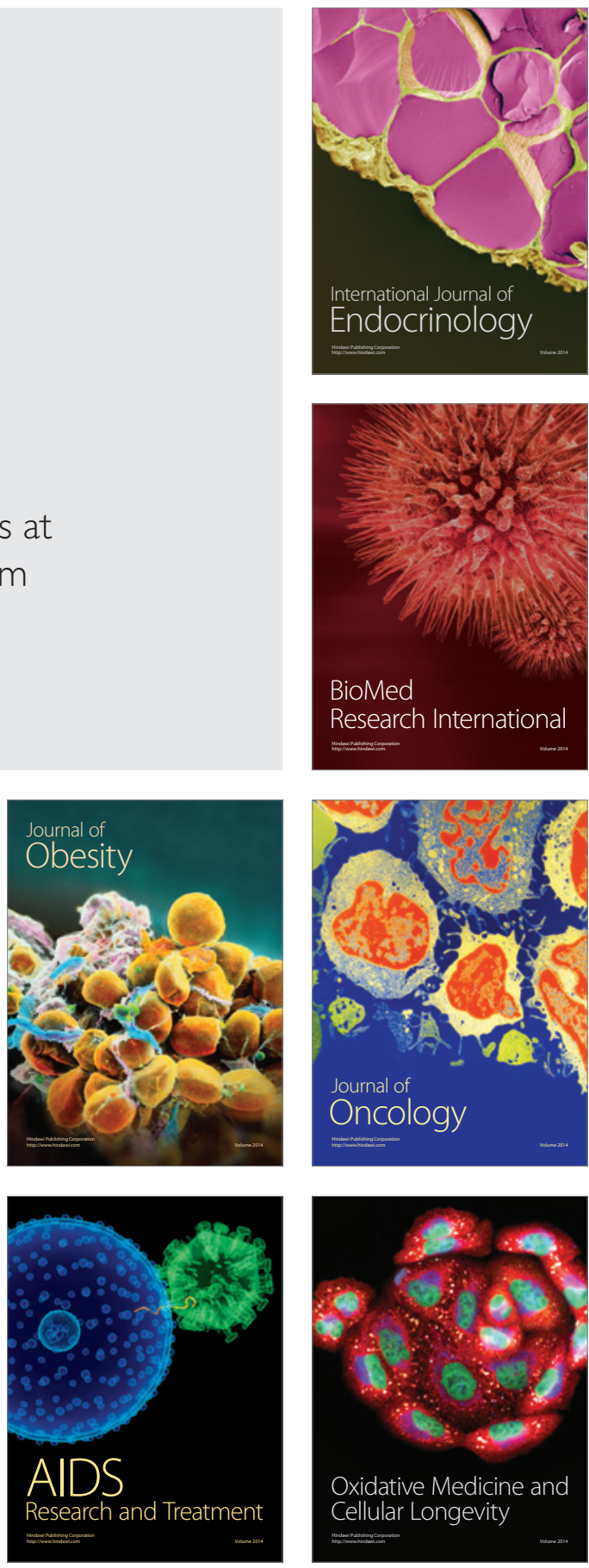